\title{
One-year clinical evaluation of the retention of resin and glass ionomer sealants on permanent first molars in children
}

\author{
Kamila Prado Graciano ${ }^{1}$, Marcos Ribeiro Moysés ${ }^{2}$, José Carlos Ribeiro², Camila A. Pazzini ${ }^{1}$, \\ Camilo Aquino Melgaço ${ }^{1}$, Joana Ramos-Jorge ${ }^{3}$
}

${ }^{1}$ Universidade Vale do Rio Verde - UNINCOR, School of Dentistry, Department of Pediatric Dentistry and Orthodontics, Três Corações, MG, Brazil

Universidade Vale do Rio Verde - UNINCOR, School of Dentistry, Department of Restorative Dentistry, Três Corações, MG, Brazil

${ }^{3}$ Universidade Federal dos Vales do Jequitinhonha e Mucuri - UFVJM, School of Dentistry, Department of Pediatric Dentistry and Orthodontics, Diamantina, MG, Brazil

\begin{abstract}
Aim: To compare the retention of glass ionomer cement (GIC) used as fissure sealant with a resinbased sealant. Methods: Six- to nine-year-old children $(n=96)$ with all permanent first molars in occlusion were examined and assigned to two groups: GIC sealant or resin-based sealant. The sealants were applied according to the manufacturers' recommendations. The assessment of sealant retention was performed at two-month interval sessions $(n=6)$, when each sample was scored according to the following criteria: complete retention, partial retention or complete loss. The visual and tactile examinations were carried out with a WHO probe, mouth mirror, air syringe and artificial light. The data were submitted to descriptive statistics and survival analysis. Results: A total of 384 occlusal surfaces were analyzed. Independent of the tooth and evaluation time, slightly better results were achieved by the resin-based sealant, but the difference was not statistically significant. Conclusions: GIC and resin-based sealants achieved similar results with regards to retention during a one-year follow-up period.
\end{abstract}

Keywords: pit and fissure sealants; resin cements; glass ionomer cements.

\section{Introduction}

Received for publication: May 13, 2015 Accepted: August 11, 2015

Correspondence to: Joana Ramos-Jorge Rua Arraial dos Forros, 215 CEP: 39.100-000, Diamantina, MG, Brazil Phone/Fax: +55 38 3531-1415 E-mail: joanaramosjorge@gmail.com
Dental caries is one of the most common oral health problems in childhood ${ }^{1}$. In recent years, guidelines and systematic reviews of the literature have recommended the use of pit and fissure sealants for populations at high risk for dental caries ${ }^{2-7}$. A Brazilian study conducted in seven- to ten-year-old children from the rural community showed that caries activity in the permanent first molars was associated with dental fluorosis and malocclusion ${ }^{8}$. Accordingly, strategies aimed at health promotion should be adopted in a large scale to minimize the prevalence of oral diseases. A systematic review of randomized clinical trials reports that pit and fissure sealants on permanent molars reduce the incidence of dental caries among children and adolescents 9 . This is in agreement with the findings of a previous study, in which the authors stated that preventive strategies involving the use of a sealant have significantly contributed to the reduction of dental caries ${ }^{10}$. Occlusal caries is most prevalent among children because of the morphology of pits and fissures, which are stagnation areas ${ }^{11}$. Thus, dental sealant acts as a mechanical barrier to the accumulation of biofilm ${ }^{12}$. 
Resin-based and glass ionomer sealants stand out among the materials employed as pit and fissure sealants ${ }^{13}$. In a review of the literature, Niederman ${ }^{14}$ stated that resin-based and glass ionomer sealants have a similar preventive effect. The fact that glass ionomer cement (GIC) recharges the fluoride in fluoridated agents, such as toothpastes and mouthwashes, contributes to the maintenance of adequate levels of fluoride in saliva ${ }^{15}$. However, the retention of GIC is reported to be insufficient ${ }^{13}$, whereas resin-based sealants exhibit satisfactory retention ${ }^{16}$.

Before broadening the use of sealants as a preventive measure in the public healthcare system, it is fundamental to establish the effectiveness of this procedure. Thus, the clinical follow up of teeth sealed with different materials is important to strengthen the scientific evidence on this issue. As the effectiveness of a sealant is associated with the retention of the material in the tooth ${ }^{17}$, the aim of the present study was to compare the retention of GIC used as a fissure sealant and a resin-based sealant in six- to nine-year-old children for a one-year follow-up period.

\section{Material and methods}

\section{Study design and sample}

This study involved the clinical follow up of children treated at the pediatric dentistry clinic of the Vale do Rio Verde University, Três Corações, Brazil. Six- to nine-yearsold children $(n=96)$, who have met the inclusion criteria after being submitted to clinical examination, were indicated to have their first permanent molars sealed $(n=384)$. A statement of informed consent was obtained from the legal guardians prior to the procedures.

The inclusion criteria were high risk of dental caries (consumption of carbohydrates three or more times a day between meals), inadequate access to fluoride (water or toothpaste), low socioeconomic level, presence of all four permanent first molars in occlusion and history of carious lesions in the primary dentition. The exclusion criteria were cavitated carious lesions, hypomineralization, restoration or sealant on the occlusal face of any of the permanent first molars and use of a removable or fixed orthodontic appliance. In addition, children who presented any systemic alteration or troublesome behavior were excluded.

One group of children received a GIC sealant (Fuji VII, GC Corporation, Tokyo, Japan) and the other group received a resin-based sealant (Delton, Dentsply, Petrópolis, RJ, Brazil). The sealant was applied after any curative dental treatment required, such as restoration, root canal or extraction was concluded. The type of sealant was selected based on the needs of each child. Children who exhibited active initial dental caries (even after the conclusion of the curative treatment) received GIC. All children received oral hygiene instructions and dietary counseling.

\section{Application of sealant}

The occlusal sealants were applied by a dentist experienced in pediatric dentistry in a university setting. Prior to application, the teeth were cleaned with water and pumice stone paste using pointed bristle brushes at low speed and then rinsed thoroughly to remove the debris. Isolation was performed using cotton rolls, with adequate suctioning to manage the salivation flow.

The teeth that received the resin-based sealant were dried with an air syringe and etched with $37 \%$ phosphoric acid (Atacktec, Rio do Sul, SC, Brazil) for $30 \mathrm{~s}$, followed by rinsing for $30 \mathrm{~s}$ and drying with an air syringe for $15 \mathrm{~s}$. Isolation was replaced before application of the resin-based sealant, which was submitted to a conventional light polymerization method (Elipar Free Light, 3M ESPE, St. Paul, MN, USA; $1200 \mathrm{~mW} /$ $\mathrm{cm}^{2}$ for $20 \mathrm{~s}$ ). All the sealed surfaces were tested for defects and additional material was added if necessary.

For application of the GIC sealant, a shallow measure of powder and one drop of liquid were used for each tooth (blending time: $1 \mathrm{~min}$ ). After drying for $15 \mathrm{~s}$ with an air syringe, the material was applied and four minutes were allowed for curing. High points were checked using articulating paper and corrected. The adjustments were performed using composite polishing burs in a single visit. The GIC sealant applications were made by three dentists experienced in pediatric dentistry.

\section{Evaluation of retention}

The evaluation of sealant retention was performed at two-month intervals $\left(2^{\text {nd }}, 4^{\text {th }}, 6^{\text {th }}, 8^{\text {th }}, 10^{\text {th }}\right.$ and $\left.12^{\text {th }}\right)$ over the course of one year. For such, visual and tactile examinations were carried out with the aid of a WHO probe, mouth mirror, air syringe and artificial light. The status of the sealant was checked and scored as complete retention (all pits and fissures filled with material), partial retention (loss of some material) or complete loss (absence of material from the entire occlusal surface). This evaluation was performed by a trained dentist, who did not participate in sealant application sessions.

\section{Statistical analysis}

Data analysis was conducted with the Statistical Package for Social Sciences (SPSS version 20.0 for Windows, SPSS Inc, Chicago, IL, USA). The data were submitted to descriptive statistics, followed by survival analysis. A KaplanMeier plot was constructed for the analysis of sealant retention at the different evaluation times. The level of significance was set to $5 \%(\mathrm{p}<0.05)$.

\section{Ethical considerations}

This study received approval from the Human Research Ethics Committee of Vale do Rio Verde University (Brazil) under protocol number 30609814.8.0000.5158. All research subjects underwent dental treatment at the School of Dentistry and provided written informed consent.

\section{Results}

Among the children who completed the study (98\%), 46 received the GIC sealant and 50 received the resin-based sealant. The distribution of children in relation to their 
characteristics (sex and age) was similar between groups. However, the number of nine-year-old children was higher in the group that received a resin-based sealant (Table 1). All occlusal surfaces of their permanent first molars were sealed and included in the study $(n=384)$. The descriptive analysis demonstrated a slightly higher percentage of complete retention of the resin-based sealant in comparison to GIC after one year. Complete retention rate was higher on the tooth 26 in both groups (Table 2). However, independent from the analyzed tooth, this difference did not achieve statistical significance (Table 3). The data are confirmed by the KaplanMeier plot, which demonstrates similar sealant retention in both groups at any given evaluation time (Figure 1).

\section{Discussion}

In the present study, a sample of children was followed up for one year for the evaluation of sealant retention on permanent first molars, since pits and fissures on these teeth are the most susceptible sites to dental caries in the permanent dentition $^{18}$.

In a recent review it was found that the use of resinbased sealants was effective in reducing dental caries ${ }^{16}$. However, no conclusion could be reached regarding the relative effectiveness of different types of sealants ${ }^{9,19}$. In another review it was found that the risk of complete loss of

Table 1: Distribution of sealants according to children's characteristics

\begin{tabular}{lcc}
\hline $\begin{array}{l}\text { Type of material } \\
\text { Characteristic of child }\end{array}$ & $\begin{array}{c}\text { Glass ionomer } \\
\text { cement } \\
\mathbf{n}(\%)\end{array}$ & $\begin{array}{c}\text { Resin-based } \\
\text { sealant } \\
\mathbf{n}(\%)\end{array}$ \\
$\begin{array}{l}\text { Sex } \\
\text { Female }\end{array}$ & $26(52.0)$ \\
Male & $25(54.3)$ & $24(48.0)$ \\
Age & $21(45.7)$ & \\
6 years & & $6(12.0)$ \\
7 years & $6(13.0)$ & $9(18.0)$ \\
8 years & $9(19.6)$ & $15(30.0)$ \\
9 years & $15(32.6)$ & $20(40.0)$ \\
\hline
\end{tabular}

Table 2: Retention of sealant according to tooth and type of materia

\begin{tabular}{lcc}
\hline $\begin{array}{l}\text { Type of material } \\
\text { Retention of sealant }\end{array}$ & $\begin{array}{c}\text { Glass ionomer } \\
\text { cement } \\
\mathbf{n}(\%)\end{array}$ & $\begin{array}{c}\text { Resin-based } \\
\text { sealant } \\
\mathbf{n}(\%)\end{array}$ \\
$\begin{array}{l}\text { Tooth 16 } \\
\text { Complete loss }\end{array}$ & $4(8.7)$ & $4(8.0)$ \\
Partial retention & $25(54.3)$ & $24(48.0)$ \\
Complete retention & $17(37.0)$ & $22(44.0)$ \\
Tooth 26 & & \\
Complete loss & $3(6.5)$ & $3(6.0)$ \\
Partial retention & $18(39.1)$ & $14(28.0)$ \\
Complete retention & $25(54.4)$ & $33(66.0)$ \\
Tooth 36 & & $6(12.0)$ \\
Complete loss & $6(13.0)$ & $17(34.0)$ \\
Partial retention & $17(37.0)$ & $27(54.0)$ \\
Complete retention & $23(50.0)$ & $6(12.0)$ \\
Tooth 46 & & $15(30.0)$ \\
Complete loss & $9(19.6)$ & $29(58.0)$ \\
Partial retention & $15(32.6)$ &
\end{tabular}

sealant retention was associated with the risk of caries occurrence for resin-based sealants, but not for ionomer-based sealants $^{20}$. Thus, although the performed meta-analysis has pointed out a low retention rate for glass ionomer cement sealants ${ }^{16}$, the retention of at least part of this material has a protective effect, unlike what occurs with resin-based sealants. These findings underscore the need to evaluate sealant retention with regard to partial retention, as performed in the present study.

Independent of the analyzed tooth, no significant difference in retention was found between the two types of material used as sealant. However, at follow-up sessions any loss of material present was considered as partial retention. The descriptive analysis demonstrated that the rate of partial retention was similar in both groups. Moreover, no significant differences were found at any given evaluation time. Although pretreatment with a suitable acid is essential to obtain adequate penetration of a sealing material ${ }^{21}$, the

Table 3: Survival analysis according to tooth and material

\begin{tabular}{lccc}
\hline $\begin{array}{l}\text { Co-variables } \\
\text { Type of material }\end{array}$ & Number of losses & Mean survival & $\begin{array}{c}\text { p-value } \\
\text { Log Rank test }\end{array}$ \\
$\begin{array}{l}\text { Tooth 16 } \\
\text { Glass ionomer cement }\end{array}$ & 29 & $7.91(6.96-8.87)$ & 0.453 \\
$\begin{array}{l}\text { Resin-based sealant } \\
\text { Tooth 26 }\end{array}$ & 28 & $8.40(7.48-9.32)$ & \\
Glass ionomer cement & 21 & $8.96(7.94-9.98)$ & 0.264 \\
Resin-based sealant & 17 & $9.68(8.74-10.62)$ & \\
$\begin{array}{l}\text { Tooth 36 } \\
\text { Glass ionomer cement }\end{array}$ & 23 & $9.00(8.08-9.92)$ & 0.707 \\
Resin-based sealant & 23 & $9.24(8.37-10.11)$ & \\
Tooth 46 & & & \\
Glass ionomer cement & 24 & $8.48(7.44-9.52)$ & 0.213 \\
Resin-based sealant & 21 & $9.40(8.51-10.29)$ & \\
\hline
\end{tabular}




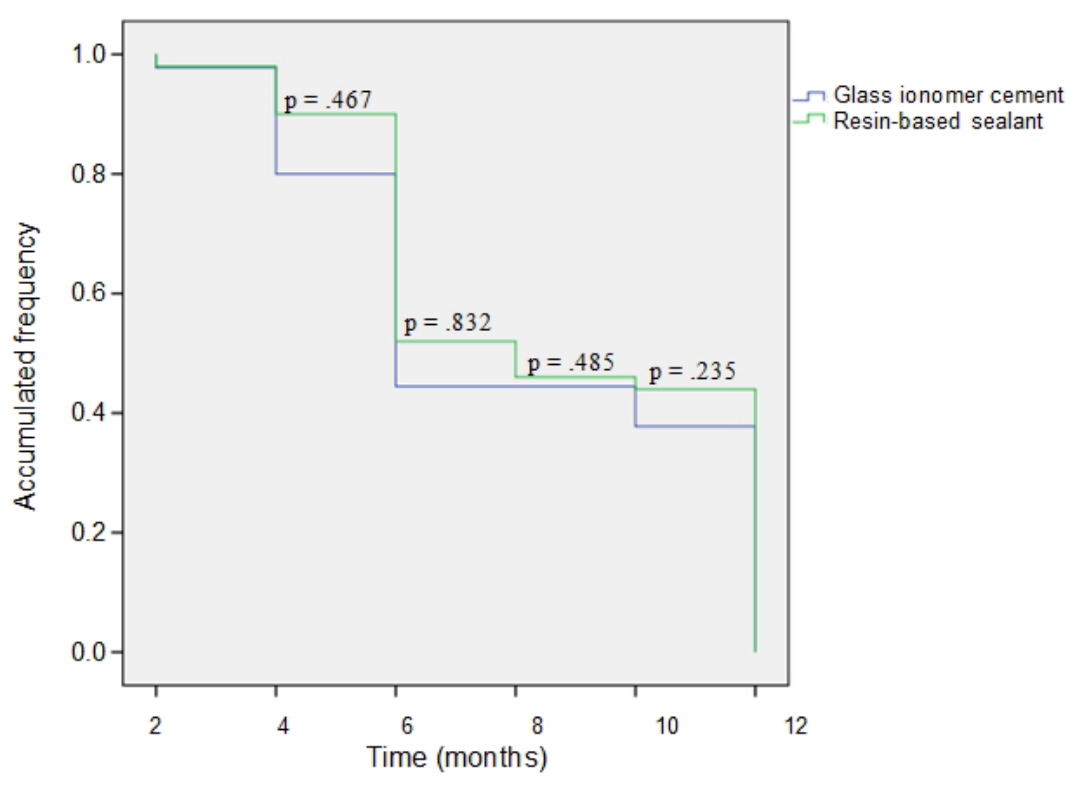

Fig. 1: Kaplan-Meier plot comparing two types of sealant

authors believe that the penetration did not influence the sealants retention since this pretreatment was not performed for the application of GIC sealants.

The initial loss of sealant may be due to technical flaws and subsequent loss is likely due to occlusal forces ${ }^{22}$. The largest loss of sealant was found at the six-month evaluation, which is in agreement with data described by Subramaniam et al. ${ }^{23}$. However, the retention rates in the present study were higher, which may be due to the improvements in the quality of the materials with time. Moreover, one factor may have contributed to this difference between the studies. The afore-mentioned study has a more robust design, in which the researchers applied resin-based sealants on teeth 16 and 46 and pink-colored GIC sealants on teeth 26 and 36. Since adding color to the sealant improves perception of the dentist, it is possible that this difference of methods also contributed to the divergent results of studies.

The present findings should be confirmed by studies with more robust designs for corroborating the comprehensive use of GIC sealants in public oral healthcare services, since resin-based sealants are technique-sensitive and influenced by patient cooperation, operator variability and contamination of the operating field ${ }^{24}$. Moreover, further studies are required with a longer follow-up period and the evaluation of the effects of such sealants on caries prevention and the control of lesions in the early stage.

During a one-year follow-up period, considering time intervals of two months, GIC and resin-based sealants achieved similar results with regards to retention.

\section{References}

1. Benzian H, Hobdell M, Holmgren C, Yee R, Monse B, Barnard JT, et al. Political priority of global oral health: an analysis of reasons for international neglect. Int Dent J. 2011; 61: 124-30.
2. Griffin SO, Oong E, Kohn W, Vidakovic B, Gooch BF, CDC Dental Sealant Systematic Review Work Group, et al. The effectiveness of sealants in managing caries lesions. J Dent Res. 2008; 87: 169-74.

3. Beauchamp J, Caufield PW, Crall JJ, Donly K, Feigal R, Gooch B, et al. Evidence-based clinical recommendations for the use of pit-and-fissure sealants: a report of the American Dental Association Council on Scientific Affairs. J Am Dent Assoc. 2008; 139: 257-68.

4. Ahovuo-Saloranta A, Hiiri A, Nordblad A, Mäkelä M, Worthington HV. Pit and fissure sealants for preventing dental decay in the permanent teeth of children and adolescents. Cochrane Database Syst Rev. 2008; 8: CD001830.

5. Gooch BF, Griffin SO, Gray SK, Kohn WG, Rozier RG, Siegal M, et al. Preventing dental caries through school-based sealant programs: updated recommendations and reviews of evidence. J Am Dent Assoc. 2009; 140: 1356-65.

6. Hiiri A, Ahovuo-Saloranta A, Nordblad A, Mäkelä M. Pit and fissure sealants versus fluoride varnishes for preventing dental decay in children and adolescents. Cochrane Database Syst Rev. 2010; 17: CD003067.

7. Mickenautsch S, Yengopal V. Caries-preventive effect of glass ionomer and resin-based fissure sealants on permanent teeth: An update of systematic review evidence. BMC Res Notes. 2011; 4: 22.

8. Motta LJ, Santos JG, Alfaya TA, Guedes CC, Godoy CHL, Bussadori SK. Clinical status of permanent first molars in children aged seven to ten years in a Brazilian rural community. Braz J Oral Sci. 2012; 11: 475-80.

9. Ahovuo-Saloranta A, Forss H, Walsh T, Hiiri A, Nordblad A, Mäkelä M, et al. Sealants for preventing dental decay in the permanent teeth. Cochrane Database Syst Rev. 2013; 3: CD001830.

10. Vieira AL, Zanella NL, Bresciani E, Barata Tde J, da Silva SM, Machado $M A$, et al. Evaluation of glass ionomer sealants placed according to the ART approach in a community with high caries experience: 1-year followup. J Appl Oral Sci. 2006; 14: 270-5.

11. Kidd EA, Smith BG, Pickard HM. Pickard's manual of operative dentistry. 6th ed. Oxford University Press; 1990.

12. Feldens EG, Feldens CA, Araujo FB, Souza MA. Invasive technique of pit and fissure sealants in primary molars: a SEM study. J Clin Pediatr Dent. 1994; 18: 187-90.

13. Seppä $L$, Forss $H, \varnothing$ gaard B. The effect of fluoride application on fluoride release and the antibacterial action of glass ionomers. J Dent Res. 1993; 72: $1310-4$ 
14. Niederman R. Glass ionomer and resin-based fissure sealants - equally effective? Evid Based Dent. 2010; 11: 10.

15. Carvalho AS, Cury JA. Fluoride release from some dental materials in different solutions. Oper Dent. 1999; 24: 14-9.

16. Kühnisch J, Mansmann U, Heinrich-Weltzien R, Hickel R. Longevity of materials for pit and fissure sealing - results from a meta-analysis. Dent Mater. 2012; 28: 298-303.

17. Bhatia MR, Patel AR, Shirol DD. Evaluation of two resin based fissure sealants: a comparative clinical study. J Indian Soc Pedod Prev Dent. 2012; 30: 227-30.

18. Sheiham A, Sabbah W. Using universal patterns of caries for planning and evaluating dental care. Caries Res. 2010; 44: 141-50.

19. Deery $C$. Strong evidence for the effectiveness of resin based sealants. Evid Based Dent. 2013; 14: 69-70.

20. Mickenautsch S, Yengopal V. Validity of sealant retention as surrogate for caries prevention - a systematic review. PLoS One. 2013; 8: e77103.

21. Markovic D, Petrovic B, Peric T, Miletic I, Andjelkovic S. The impact of fissure depth and enamel conditioning protocols on glass-ionomer and resin-based fissure sealant penetration. JAdhes Dent. 2011; 13: 171-8.

22. Messer LB, Calache H, Morgan MV. The retention of pit and fissure sealants placed in primary school children by Dental Health Services, Victoria. Aust Dent J. 1997; 42: 233-9.

23. Subramaniam P, Konde S, Mandanna DK. Retention of a resin-based sealant and a glass ionomer used as a fissure sealant: a comparative clinical study. J Indian Soc Pedod Prev Dent. 2008; 26: 114-20.

24. Karlzen-Reuterving $\mathrm{G}$, van Dijken JW. A three-year follow-up of glass ionomer cement and resin fissure sealants. ASDC J Dent Child. 1995; 62: 108-10. 